\title{
Someday My Prince Will Come: Unemployment, Income Transfer and International Factor Movement
}

\author{
Shigemi Yabuuchi ${ }^{\mathrm{a}^{*}}$
}

${ }^{a}$ Nagoya City University

\begin{abstract}
Unemployment has been observed in developed countries as well as developing countries. The unemployed in the developed countries can be characterized as being dependent because they have excessive expectations of their jobs and rely on others for a living. This type of unemployment has been increasing, particularly among the younger generation in industrialized countries, for example, Japan. On the other hand, there has been an extensive movement of labor among countries. Thus, this paper investigates the effects of international labor (as well as capital) movement on unemployment, particularly when there is income transfer to the unemployed workers.
\end{abstract}

JEL Classification: F16, J61, R13

Keywords: Unemployment, income transfer, international factor movement

\section{Introduction}

In certain developed countries, there has been a remarkable increase in unemployment of the younger generation. This type of unemployment is characterized as being dependent because the unemployed have excessive expectations of their jobs and rely on others for a living. In other words, the youth can be employed in certain suitable industries if they wish. However, they prefer to be unemployed in the hope that someday they can obtain their ideal jobs. They are not unlike Snow White, who believes that "someday my prince will come". This is highly similar to the situation in developing countries. In those countries, rural workers are attracted to "the city lights" and migrate to the urban

* Contact address: Shigemi Yabuuchi, Department of Economics, Nagoya City University, Yamanohata, Mizuho, Nagoya 467-8501, Japan. Tel \& Fax: +81-52-872-5739. Email: yabuuchi@econ.nagoya-cu.ac.jp. I would like to express my thanks to Tran-Nam Binh and an anonymous referee for many useful comments and suggestions, and participants at the $7^{\text {th }}$ European Trade Study Group Conference held at University College Dublin. Financial support from the Japan Society for the Promotion of Science (Grants-in-Aid for Scientific Research, no. c-2-16530156) is greatly acknowledged. 
area at the risk of unemployment, although they can be fully employed in the rural area at the prevailing rural wage rate. Harris and Todaro (1970) formulated this labor allocation mechanism between the rural and urban areas in the developing countries. Thus, the problem of unemployment of the younger generation can be analyzed by adopting their approach. Various aspects of the Harris-Todaro (hereafter "HT") model have been discussed by several trade theorists such as Bhagwati and Srinivasan (1974), Corden and Findlay (1975), Khan (1980), Batra and Naqvi (1987), Beladi and Naqvi (1988), Hazari and Sgro (1991), Marjit (1991), Neary (1981), Gupta (1993), Yabuuchi (1993), Chao and Yu (1996) and Chaudhuri (2005).

This analysis is an extension of the mobile-capital HT model developed by Corden and Findlay (1975) and followed by Batra and Naqvi (1987) and Yabuuchi (2006) among others. Yabuuchi (2006) introduces the difference between skilled-labor and unskilled-labor and the third sector into the standard mobile-capital HT model and analyzes the relation between unemployment and the international movement of two types of labor and capital by paying special attention to the existence of the third sector as a labor absorbing sector. In this three sector model, the effects of production subsidies, wage policy and immigration on unemployment of both skilled and unskilled labor are examined. This paper, however, examines the unemployment problem of the younger generation in developed countries by explicitly introducing financial support for the unemployed workers into the two sector HT model with skilled labor in one (advanced) sector. This is because there are some similarities between rural workers in developing countries and unskilled youth in developed countries in the sense that labor allocation is based on the expected wage income and some transfer mechanism of subsistence income. Actually, the income transfer from the parents is the characteristic feature of this sort of unemployment.

The unemployment in the HT model is inherently involuntary because it is caused by the fixed wage rate in one sector of the economy. However, it has an aspect of dependent unemployment in a sense that they are supported by others, for example, the family, relatives and society. This is also true for the unemployment of the unskilled younger generation in developed countries because the unemployed are dependent and self-indulgent. Therefore, it seems that unemployment itself is not a serious problem for the workers themselves. Whether or not they are employed in a suitable job is merely their choice. However, this might cause social instability or loss of the opportunity for the accumulation of technical knowledge in the most appropriate period, if the period of being without a job is long. This type of unemployment is sometimes called NEET (Not in Employment, Education or Training). They tend to remain unemployed and unskilled. In these respects, therefore, this problem is an extremely important concern for the country as a whole as well as the unemployed workers themselves. Subsequently, we consider the efficient policies to reduce this type of unemployment.

The remainder of this paper is organized as follows. Section 2 presents the model and basic assumptions. Section 3 examines the effects of international factor movement on unemployment. The concluding remarks are provided in section 4. 


\section{The Model and Assumptions}

Consider a small open economy in which there are two sectors. One sector produces good $1, X_{1}$, and the other sector produces good 2, $X_{2}$. Suppose sector 2 is attractive and sector 1 is not attractive to the workers. For simplicity, sectors 1 and 2 are labeled as traditional and advanced manufacturing sectors, respectively. Production of good 1 requires unskilled-labor $\left(L_{1}\right)$ and capital $\left(K_{1}\right)$, while production of good 2 requires unskilled-labor $\left(L_{2}\right)$, skilled-labor $\left(H_{2}\right)$ and capital $\left(\mathrm{K}_{2}\right)$. Thus, the production functions are as follows:

$$
\begin{aligned}
& X_{1}=F^{1}\left(L_{1}, K_{1}\right), \\
& X_{2}=F^{2}\left(L_{2}, H_{2}, K_{2}\right) .
\end{aligned}
$$

It is assumed that $F^{j}$ has positive and diminishing marginal products and it is homogeneous of degree one. Suppose unskilled labor mainly consists of younger generation.

Under perfect competition, the following is derived:

$$
\begin{aligned}
& p_{1}=a_{L 1} w_{1}+a_{K 1} r, \\
& p_{2}=a_{L 2} w_{2}+a_{H 2} s+a_{K 2} r
\end{aligned}
$$

where $a_{i j}$ is the amount of the $i$ th factor used in the $j$ th industry to produce one unit of the output, $w_{j}$ is the wage rate of unskilled labor in the jth sector, $s$ is the wage rate of skilled labor, $r$ is rental of capital, and $p_{j}$ is the price of the $j$ th $\operatorname{good}(j=1,2)$. It is assumed that all goods are tradable and then their prices are exogenously given.

In the standard HT model, it is assumed that the wage rate in (manufacturing) sector $2\left(w_{2}\right)$ is set at a relatively high level, and it is rigid due to some political and/or institutional considerations, while the wage rate in (agricultural) sector $1\left(w_{1}\right)$ is flexible. In this situation, the rural workers have two alternatives of staying in rural areas in order to obtain a job at a low wage rate or migrating to urban areas in order to seek a high wage income at the risk of unemployment. Thus, the labor allocation mechanism between the sectors is shown as follows:

$$
w_{1}=w_{2} L_{2} /\left(L_{2}+L_{u}\right) \text { or } w_{1}(1+\lambda)=w_{2},
$$

where $L_{2}$ and $L_{u}$ are the employed and unemployed labor in the urban area, respectively, and $\lambda=L_{u} / L_{2}$. In the labor market equilibrium, therefore, the wage rate in sector $1\left(w_{1}\right)$ equals the expected wage income in sector 2 , which equals the manufacturing wage rate $\left(w_{2}\right)$ times the probability of finding a job in the urban manufacturing sector $\left(L_{2} /\left(L_{2}+\right.\right.$ $\left.L_{u}\right)$ ).

This labor allocation mechanism is applied to the job search behavior of unskilled labor in developed countries. Thus, the unskilled labor can obtain secure (but boring) jobs in the labor-absorbing sector (for example, traditional manufacturing sector) at 
a low wage rate, while simultaneously they can seek high wage and/or attractive jobs at the risk of unemployment in other sectors (for example, advanced hi-tech sector). This seems to reflect the behavior of several young unskilled job-seekers in developed countries. On the basis of HT model, it is assumed that the advanced-sector wage rate is fixed at a higher level than the traditional-sector wage rate. This is because the firms in the advanced sector have well organized trade unions and/or there might be certain agreements or laws on the level of the minimum wage rate. Alternatively, it might be argued that the high and constant wage rate in the sector captures various types of benefits for the workers, which include pecuniary rewards, stability, and interest in the job. It is also assumed that skilled labor is fully employed in the advanced sector.

In the HT labor allocation mechanism, it is implicitly assumed that unemployed labor is supported by employed labor, such as other members of the family, or a job is allocated daily (or monthly) to all applicants by lottery. Otherwise, unemployed labor cannot survive since unemployment allowance is not considered in the standard HT model. The former assumption fits well into the present set-up. The unemployed young people are supported by the advanced generation, for example, their parents and/or grandparents. They are rather wealthy, and they are often willing to support their children or grandchildren. This phenomenon has been increasingly observed in the Japanese society.

Subsequently, this mechanism is explicitly introduced into the standard HT labor allocation mechanism as follows:

$$
w_{1}=w_{2} L_{2} /\left(L_{2}+L_{u}\right)+\alpha w_{2} L_{u} /\left(L_{2}+L_{u}\right)
$$

or

$$
w_{1}(1+\lambda)=w_{2}(1+\alpha \lambda)
$$

In other words, it is assumed that the unemployed obtain a certain amount of income $\left(\alpha w_{2}\right)$ as a gift. The gift can be considered as unemployment allowance, subsidies on education and/or training, and generous support from their relatives. The amount or the level of $\alpha(0<\alpha<1)$ depends on the characteristic feature of the society. It is not unrealistic to assume that $w_{1}>\alpha w_{2}$. It is also assumed that the necessary "fund" is collected in a lump-sum manner. This might be justified as a first approach to this issue. For further examination, the agents who supply the fund to the unemployed have to be specified.

Exogenously given endowments impose the following resource constraints:

$$
\begin{aligned}
& a_{L 1} X_{1}+a_{L 2} X_{2}+\lambda a_{L 2} X_{2}=L+L^{*}, \\
& a_{H 2} X_{2}=H+H^{*},
\end{aligned}
$$

and

$$
a_{K 1} X_{1}+a_{K 2} X_{2}=K+K^{*}
$$

where $L, H$, and $K$ are the domestic endowments of unskilled labor, skilled labor, and capital, respectively, while $L^{*}, H^{*}$, and $K^{*}$ are the foreign inflows of unskilled labor, skilled labor, and capital, respectively. This completes the specification of the model with the fixed endowment of factors and the internationally determined prices. The six 
unknown variables, $w_{1}, s, r, X_{1}, X_{2}$, and $\lambda$, are solved by six equations (3)-(8) with their given parameters, $w_{2}, p_{1}, p_{2}, L, H, K, L^{*}, H^{*}$, and $K^{*}$.

In the following discussion, the factor intensities between factors play an important role. In this case, the following assumptions are made:

Assumption 1: Advanced sector 2 is capital-intensive relative to unskilled-labor compared to traditional sector 1 in the value sense, i.e.

$$
\begin{aligned}
& r K_{2} / w_{2} L_{2}>r K_{1} / w_{1} L_{1} \Leftrightarrow k_{2}>(1+\lambda) k_{1} /(1+\alpha \lambda) \\
& \Leftrightarrow \Lambda_{L K} \equiv \lambda_{L 1} \lambda_{K 2}-(1+\lambda) \lambda_{L 2} \lambda_{K 1} /(1+\alpha \lambda)>0,
\end{aligned}
$$

where $k_{j}=K_{j} / L_{j},(j=1,2)$, and $\lambda_{i j}$ the allocative share of the $i$ th factor in the $j$ th industry (e.g. $\lambda_{K 2}=a_{K 2} X_{2} / K$ ).

This assumption is the modified version of the Khan-Neary stability condition that is well known in the literature (i.e. $\left.k_{2}>(1+\lambda) k_{1}\right)$.

\section{International Factor Movement and Unemployment}

\subsection{Immigration of unskilled labor}

First, the effect of an inflow of unskilled foreign labor on the rate of unemployment $(\lambda)$ is examined. $\lambda$ shows the ratio of the unemployed to employed labor in the advanced sector. It is not the rate of unemployment in the economy as a whole. However, it plays an important role in the analysis of HT model and used as a variable to show the degree of unemployment.

Comparative statics yields (see Appendix A):

$$
\left(1 / l^{*}\right)\left(\hat{\lambda} / \hat{L}^{*}\right)=-w_{1}(1+\lambda) \lambda_{K 1} \theta_{K 1} \theta_{H 1} / \Delta
$$

where $\theta_{i j}$ is the distributive share of the $i$ th factor in the $j$ th industry (e.g. $\theta_{K 1}=r a_{K 1} / p_{1}$ ), $\Delta$ is the value of the determinant of the coefficient matrix of the system, and $\Delta<0$ if the system is stable (see Appendix B). Thus, we may state the following proposition:

Proposition 1: The increase in foreign unskilled labor increases the rate of unemployment.

The result is rather straightforward and consistent with the prediction. In fact, considerable legal and illegal unskilled labor is employed in certain industries characterized by low wage and dirty, dull, dangerous and demanding conditions. Most people in developed countries do not want to work in such industries even if they are unskilled. This tendency is observed quite clearly among young people. Then, foreign workers replace domestic ones in these industries. Domestic workers quit and seek jobs in other attractive industries. However, sufficient jobs are not available for all of 
them. Thus, this provides a partial explanation of why unemployment of the younger generation has been increasing.

Thus, the simple solution for the problem is to limit the immigration of unskilled labor. There are other reasons for the increase in unemployment, such as recession and the change in the work ethic of the people. However, such an economy is in the vicious cycle of excess labor, low wage, outflow of domestic labor and further inflow of foreign labor. Therefore, the policy of reducing the inflow of unskilled labor is effective in decreasing the rate of unemployment in the advanced sector.

This result is also interesting in consideration of the development of the HT model itself. Corden and Findlay (1975) formulated the mobile-capital HT model. However, the model has the property that labor growth causes unemployment to fall and capital accumulation causes it to rise. This is rather paradoxical and lowers the credibility of the model. Subsequently, Beladi and Naqvi (1988) restored the credibility by showing that labor growth causes the rate of unemployment to rise and capital accumulation causes it to fall if another specific factor (land) is introduced into the agricultural sector. The result of this study confirms Beladi and Naqvi's result on labor growth in the case where there exists another factor (skilled labor) in the advanced industry, that is, the manufacturing industry in the original HT model.

\subsection{Immigration of skilled labor}

Now consider the effect of the inflow of skilled labor on unemployment. Solving the system for $\hat{\lambda}$ with respect to $\hat{H}^{*}$, the following is derived:

$$
\left(1 / h^{*}\right)\left(\hat{\lambda} / \hat{H}^{*}\right)=-(1+\lambda) w_{1} \theta_{K 1} \theta_{H 2} \bar{\Lambda}_{L K} / \Delta
$$

where $h^{*} \equiv H^{*} / H$ and $\bar{\Lambda}_{L K}=\lambda_{L 1} \lambda_{K 2}-(1+\lambda) \lambda_{L 2} \lambda_{K 1}$.

Thus, it can be observed that the result depends on the factor intensity among factors. This result can be summarized in the following proposition:

Proposition 2: Under Assumption 1, the increase in (foreign) skilled labor increases the rate of unemployment if $k_{2}>(1+\lambda) k_{1}$, and it decreases the rate of unemployment if $(1+$ $\lambda) k_{1}>k_{2}>(1+\lambda) k_{1} /(1+\alpha \lambda)$.

The proposition shows the possibility that the inflow of foreign skilled labor decreases unemployment. For example, this might occur when the domestic firms recruit skillful engineers or excellent professionals from abroad. The results are primarily attributed to the Rybczynski effect due to the increase in skilled labor. Since skilled labor is used only in the advanced sector, the increase in skilled labor expands the output of the advanced sector and contracts that of the traditional sector. This induces capital from the traditional sector to the advanced sector. This, in turn, increases the marginal value product of unskilled labor in the advanced sector and expands employment in the sector.

If $k_{2}$ is sufficiently large (in the sense that $k_{2}>(1+\lambda) k_{1}$ ), the increase in $L_{2}$ due to the capital inflow from the advanced sector is relatively small while the decrease in $L_{1}$ 
due to the capital outflow into the sector is relatively large. Thus, the advanced sector absorbs only a part of unskilled labor released from the traditional sector. In other words, some of the workers cannot obtain jobs in the advanced sector. This leads to the increase in the rate of unemployment. On the other hand, if $k_{2}$ is sufficiently small (in the sense that if $\left.(1+\lambda) k_{1}>k_{2}>(1+\lambda) k_{1} /(1+\alpha \lambda)\right)$, the increase in $L_{2}$ becomes relatively large when capital is induced from the traditional sector to the advanced sector. Thus, the advanced sector absorbs unskilled labor from the unemployed pool as well as that released from the traditional sector. In this case, therefore, the rate of unemployment decreases eventually.

Note that if there is no income transfer (i.e. $\alpha=0$ ), then Assumption 1 is reduced to $k_{2}>(1+\lambda) k_{1}$. In this case, therefore, there is no possibility that the inflow of skilled labor decreases the rate of unemployment. Thus, the result is very pessimistic, and it confirms that "your prince(ss) will never come". However, the result also shows that the inflow of skilled labor may decrease the rate of unemployment by expanding the attractive advanced sector if the income transfer is introduced explicitly.

\subsection{Capital inflow}

The effect of foreign capital inflow on unemployment is examined similarly. In this case

$$
\left(1 / k^{*}\right)\left(\hat{\lambda} / \hat{K}^{*}\right)=-(1+\lambda) w_{1} \lambda_{L 1} \theta_{K 1} \theta_{H 2} / \Delta,
$$

where $k^{*} \equiv K^{*} / K$.

Thus, the proposition given below follows.

Proposition 3: The increase in (foreign) capital decreases the rate of unemployment.

The result confirms the result obtained by Beladi and Naqvi (1988) in the HT model with land in the agricultural sector. In the present case, the increase in (foreign) capital expands the output of the advanced sector and contracts that of the traditional sector. This induces unskilled labor as well as capital from the traditional sector to the advanced sector. The change in unemployment is not certain. However, our result shows that the increase in $L_{2}$ is larger than the increase in $L_{u}$ even if unemployment increases.

\section{Concluding Remarks}

A problem of unemployment observed in developed countries has been analyzed by applying the so-called Harris-Todaro model. This type of unemployment is characterized as being dependent because the unemployed have excessive expectations of their jobs and rely on others for a living. It has been increasing, especially among the younger generation, in industrialized countries, for example, Japan. On the other hand, there is an extensive movement of labor and capital among countries. Thus, this paper investigates 
the effects of international factor movement on unemployment by introducing the income transfer to the unemployed workers explicitly.

It has been shown that the inflow of capital can reduce unemployment while the inflow of unskilled labor can increase unemployment. The effect of the inflow of skilled labor on the rate of unemployment depends on the factor intensity among sectors. It is shown that the inflow of skilled labor may decrease the rate of unemployment if the income transfer is introduced explicitly. The analysis is a first attempt to approach the problem. However, it presents a useful framework by suggesting an important relation between the unemployment of the unskilled younger generation and that of the original HT model.

\section{Appendix A: Comparative Statics}

Differentiating (3) to (8), the following is obtained:

$$
\left[\begin{array}{cccccc}
0 & \theta_{H 2} & \theta_{K 2} & 0 & 0 & 0 \\
\theta_{L 1} & 0 & \theta_{K 1} & 0 & 0 & 0 \\
\lambda_{L 1} S_{L L}^{1} & (1+\lambda) \lambda_{L 2} S_{L H}^{2} & A & (1+\lambda) \lambda_{L 2} & \lambda_{L 1} & \lambda \lambda_{L 2} \\
0 & S_{H H}^{2} & S_{H K}^{2} & 1 & 0 & 0 \\
\lambda_{K 1} S_{K L}^{1} & \lambda_{K 2} S_{K H}^{2} & B & \lambda_{K 2} & \lambda_{K 1} & 0 \\
(1+\lambda) w_{1} & 0 & 0 & 0 & 0 & G
\end{array}\right]\left[\begin{array}{c}
\hat{w}_{1} \\
\hat{s} \\
\hat{r} \\
\hat{X}_{2} \\
\hat{X}_{1} \\
\hat{\lambda}
\end{array}\right]=\left[\begin{array}{c}
\hat{p}_{2} \\
\hat{p}_{1} \\
l^{*} \hat{L}^{*} \\
h^{*} \hat{H}^{*} \\
k * \hat{K}^{*} \\
\alpha \lambda w_{2} \hat{\alpha}
\end{array}\right]
$$

where $l * \equiv L * / L, \quad h * \equiv H * / H, \quad k * \equiv K * / K, \quad G=\lambda\left(w_{1}-\alpha w_{2}\right)$, $A \equiv(1+\lambda) \lambda_{L 2} S_{L K}^{2}+\lambda_{L 1} S_{L K}^{1}>0, B \equiv \lambda_{K 2} S_{K K}^{2}+\lambda_{K 1} S_{K K}^{1}<0$, and $S_{L H}^{2} \equiv\left(s / a_{L 2}\right)\left(\partial a_{L 2} / \partial s\right)$, and so on.

Solving (A1) for $\hat{\lambda}$ with respect to $\hat{L} *$, equation (9) is obtained in the main text. Other results on comparative statics are similarly obtained.

\section{Appendix B: Stability}

Under the present setup, the dynamic adjustment process for the supply side of the model is specified as follows:

$$
\begin{aligned}
& \dot{X}_{1}=d_{1}\left(p_{1}-a_{L 1} w_{1}-a_{K 1} r\right) \\
& \dot{X}_{2}=d_{2}\left(p_{2}-a_{L 2} w_{2}-a_{H 2} s-a_{K 2} r\right) \\
& \dot{w}_{1}=d_{3}\left\{a_{L 1} X_{1}+a_{L 2} X_{2}+\lambda a_{L 2} X_{2}-\left(L+L^{*}\right)\right\} \\
& \dot{s}=d_{4}\left\{a_{H 2} X_{2}-\left(H+H^{*}\right)\right\} \\
& \dot{r}=d_{5}\left\{a_{K 1} X_{1}+a_{K 2} X_{2}-\left(K+K^{*}\right)\right\}
\end{aligned}
$$




$$
\dot{\lambda}=d_{6}\left\{w_{2}-(1+\lambda) w_{1} /(1+\alpha \lambda)\right\}
$$

where "." denotes differentiation with respect to time and $d_{j}$ is the positive coefficient measuring the speed of adjustment. A Marshallian adjustment process is assumed with quantities adjusting as the demand price (i.e. the exogenously given good price) differs from the supply price (i.e. the average cost of producing a given commodity) in the goods markets. In factor markets, there is a Walrasian adjustment mechanism with the fixed endowment assumption implying that returns will have to adjust.

The Jacobian matrix of the system of simultaneous equations (A2)-(A7) is

$$
J=\frac{d_{1} \cdots d_{6} w_{1} s r \lambda X_{1} X_{2}}{p_{1} p_{2} L H K}\left[\begin{array}{cccccc}
0 & 0 & 0 & -\theta_{H 2} & -\theta_{K 2} & 0 \\
0 & 0 & -\theta_{L 1} & 0 & -\theta_{K 1} & 0 \\
\lambda_{L 1} & (1+\lambda) \lambda_{L 2} & \lambda_{L 1} S_{L L}^{1} & (1+\lambda) \lambda_{L 2} S_{L H}^{2} & A & \lambda \lambda_{L 2} \\
0 & \lambda_{H 2} & 0 & S_{H H}^{2} & S_{H K}^{2} & 0 \\
\lambda_{K 1} & \lambda_{K 2} & \lambda_{K 1} S_{K L}^{1} & \lambda_{K 2} S_{K H}^{2} & B & 0 \\
0 & 0 & -(1+\lambda) w_{1} & 0 & 0 & -G
\end{array}\right]
$$

Therefore,

$$
|J|=-\left(d_{1} d_{2} d_{3} d_{4} d_{5} d_{6} w_{1} s r X_{1} X_{2} / p_{1} p_{2} p_{3} L K V\right) \Delta
$$

According to the Routh-Hurwitz theorem, a necessary condition for the local stability of the system is that $\operatorname{sign}|J|=(-1)^{k}$, where $k$ is the row (and hence, column) number of the system of the simultaneous equations. Hence, we assume that our equilibrium is stable, which implies that $|J|>0$, therefore $\Delta<0$ from (A9).

\section{References}

Batra, R. N. and N. Naqvi, 1987, "Urban Unemployment and the Gains from Trade," Economica 54, 381-395.

Beladi, H. and N. Naqvi, 1988, "Urban Unemployment and Non-Immiserizing Growth," Journal of Development Economics 28, 365-376.

Bhagwati, J. N. and T. N. Srinivasan, 1974, "On Reanalysing the Harris-Todaro Model: Policy Rankings in the Case of Sector-Specific Sticky Wages," American Economic Review 64, 502-508.

Chao, C. C. and E. S. H. Yu, 1996, "International Capital Mobility, Urban Unemployment and Welfare," Southern Economic Journal 62, 486-492.

Chaudhuri, S., 2005, "Labour Market Distortion, Technology Transfer and Gainful Effects of Foreign Capital," The Manchester School 73, 214-227.

Corden, W. M. and R. Findlay, 1975, "Urban Unemployment, Intersectoral Capital Mobility and Development Policy in a Dual Economy," Economica 42, 59-78. 
Gupta, M. R., 1993, "Rural-urban Migration, Informal Sector and Development Policies," Journal of Development Economics 41, 137-151.

Harris, J. R. and M. Todaro, 1970, "Migration, Unemployment and Development: A Two-Sector Analysis," American Economic Review 60, 126-142.

Hazari, B. R. and P. M. Sgro, 1991, "Urban-Rural Structural Adjustment, Urban Unemployment with Traded and Non-traded Goods," Journal of Development Economics 35, 187-196.

Khan, M. A., 1980, "Dynamic Stability, Wage Subsidies and the Generalized HarrisTodaro Model," Pakistan Economic Review 19, 1-24.

Marjit, S., 1991, "Agro-Based Industry and Rural Urban Migration - A Case for an Urban Employment Subsidy," Journal of Development Economics 35, 393-398.

Neary, J. P., 1981, "On the Harris-Todaro Model with Intersectoral Capital Mobility," Economica 48, 219-234.

Yabuuchi, S., 1993, “Urban Unemployment, International Capital Mobility and Development Policy," Journal of Development Economics 41, 399-403.

Yabuuchi, S., 2006, "Immigration and Unemployment of Skilled and Unskilled Labor," mimeo. 